\title{
Dependence of late glacial sea-level predictions on 3D Earth structure
}

Meike Bagge $^{1}$, Volker Klemann ${ }^{1}$, Bernhard Steinberger ${ }^{1,2}$, Milena Latinović ${ }^{1,3}$, Maik Thomas ${ }^{1,3}$

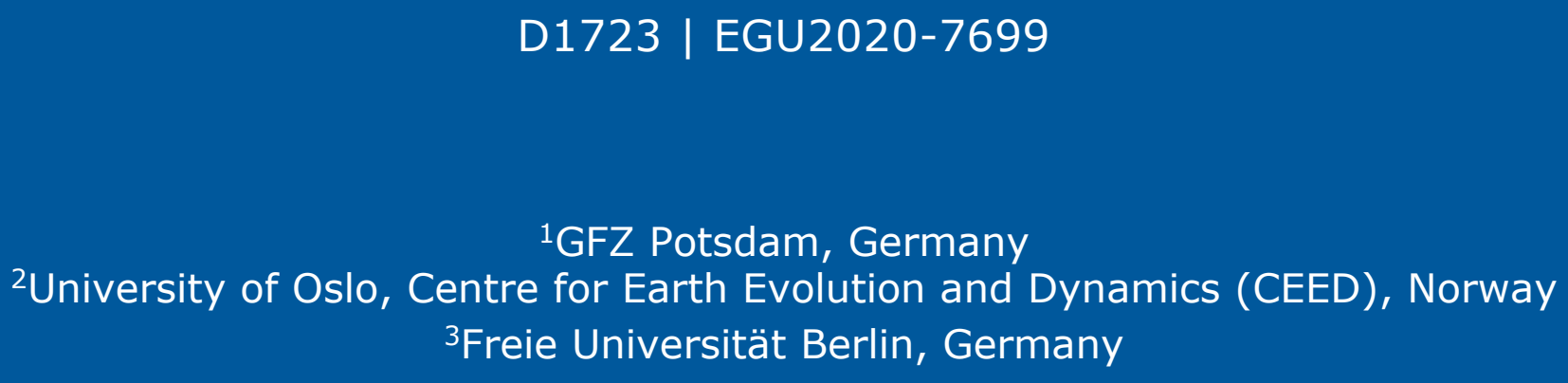

${ }^{1}$ GFZ Potsdam, Germany

${ }^{2}$ University of Oslo, Centre for Earth Evolution and Dynamics (CEED), Norway

${ }^{3}$ Freie Universität Berlin, Germany 


\section{(c) (1)}

\section{Overview}

We apply the spectral finite-element code VILMA (VIscoelastic Lithosphere and MAntle model) solving the sea-level equation in the time domain accounting for gravity, moving coastlines and mass conservation on top of a 3D viscoelastically deforming Earth (Hagedoorn et al. 2007, Martinec 2000, Klemann et al. 2008).

1. We consider viscosity structures (geodynamically constrained by geoid, heat flux, Haskell average) which are derived from seismic tomography and mantle dynamics based on Steinberger (2016) and Steinberger \& Calderwood (2006).

2. We predict the relative sea-level (RSL) during the last deglaciation applying a standard glaciation history (ICE-5G, Peltier 2004) but elaborate the impact of lateral heterogeneity in viscosity.

3. We compare the results with 1D model results and validate them with relative sea-level data (example for Central Oregon Coast). 


\section{Variability in 3D Earth structure}

a) Variation 1

$\log _{10}[$ Visc. (Pa s)]

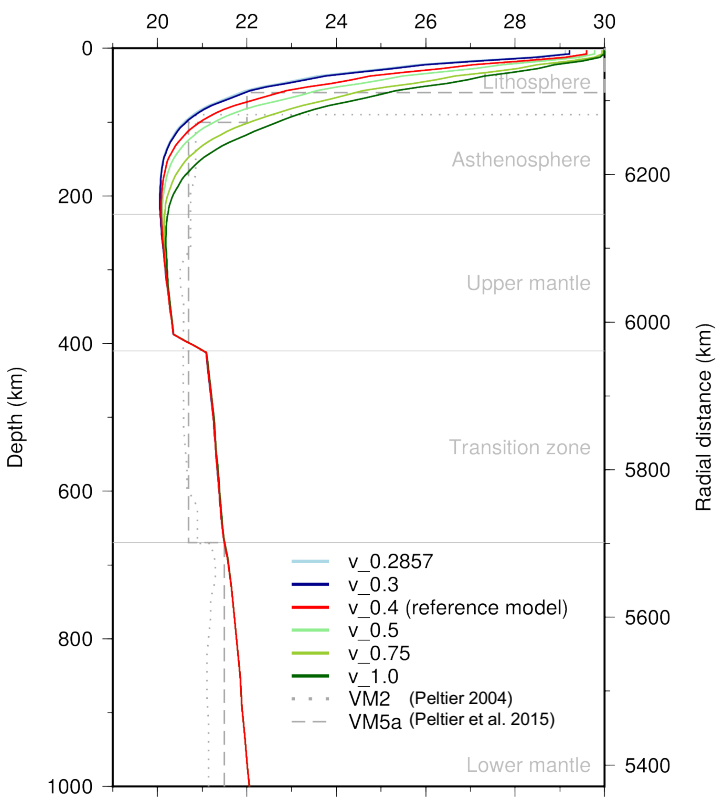

b) Variation 2

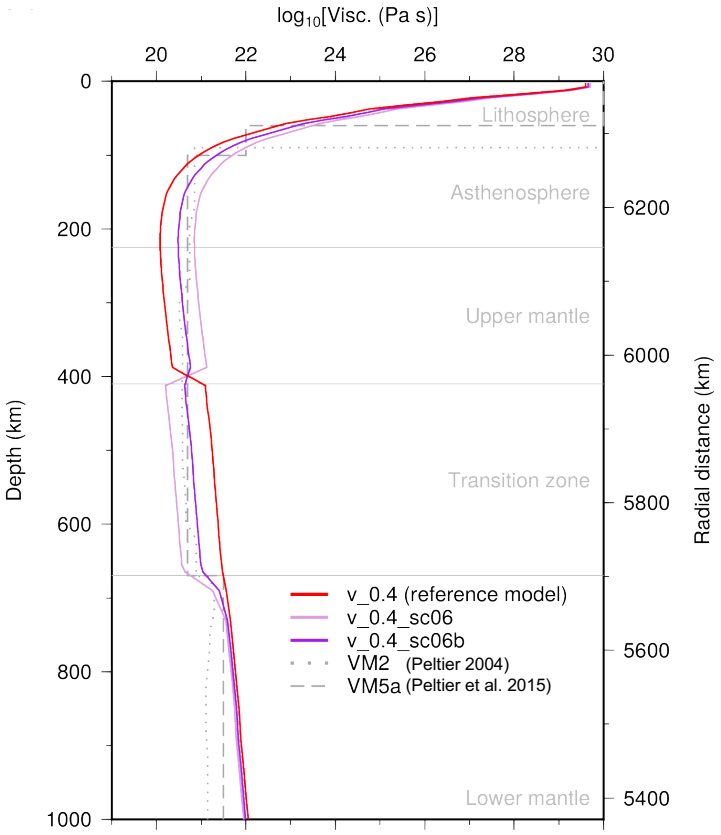

Variability due to conversion from seismic velocities to viscosity.

(Steinberger 2016, Steinberger \& Calderwood 2006)

- Variation 1: change in reducing factor $r(0.2857$ to 1$)$ $\eta \sim \exp [r H /(R T)]$

viscosity $\eta$, activation enthalpy $H$, universal gas constant $R$, temperature $T$

- Variation 2: different reference viscosity profiles

- Variation 3: scaling from seismic velocity to temperature variations increased by $4 / 3$ and 5/3 (v_0.4_4:3, v_0.4_5:3), not shown

Ensemble of ten 3D structures

Global mean of 3D Earth structures 


\section{(c) (1)}

1. Variability in 3D Earth structure

a) Lithospheric thickness

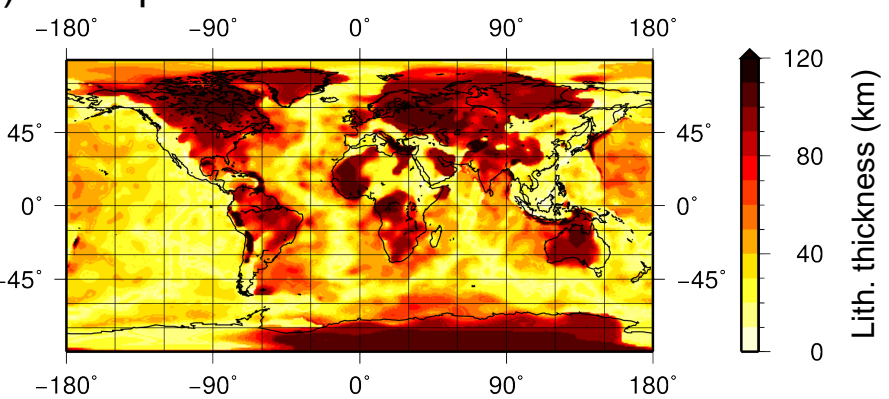

c) Upper mantle (viscosity)

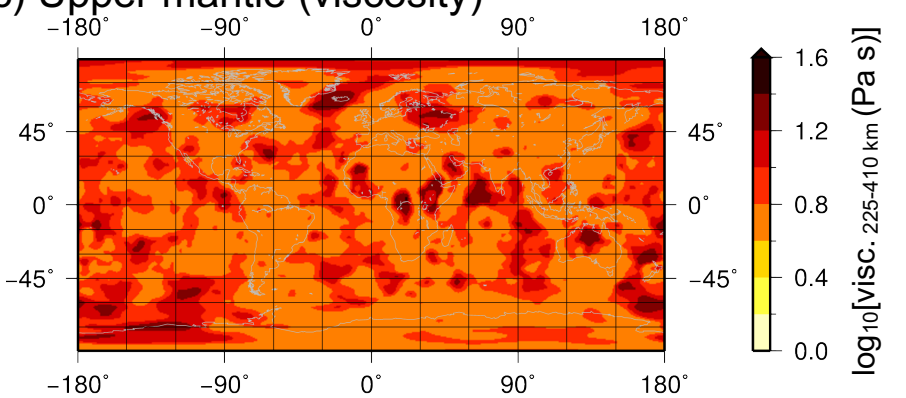

b) Asthenosphere (viscosity)

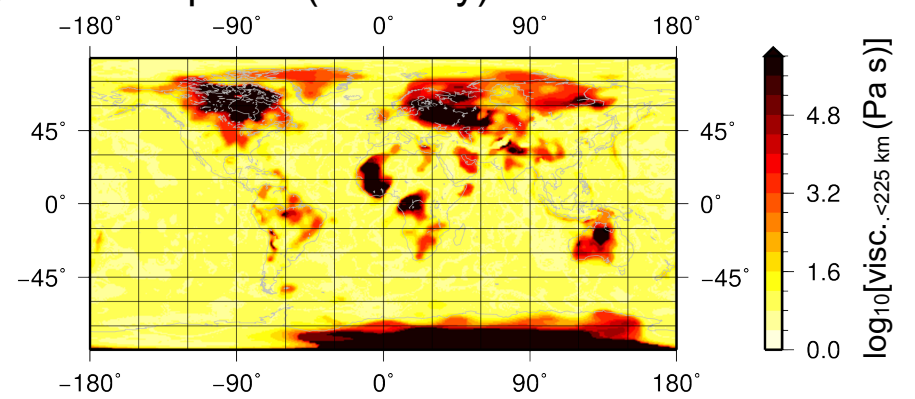

d) Transition zone (viscosity)

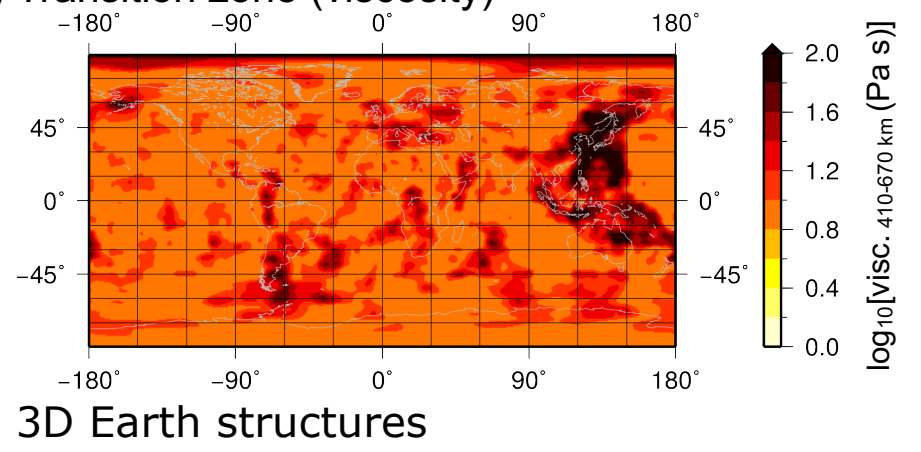

Significant variability between 3D Earth structures Ensemble range of ten 3D Earth structures

\section{GF Z}




\section{Variability in predicted RSL}

a)

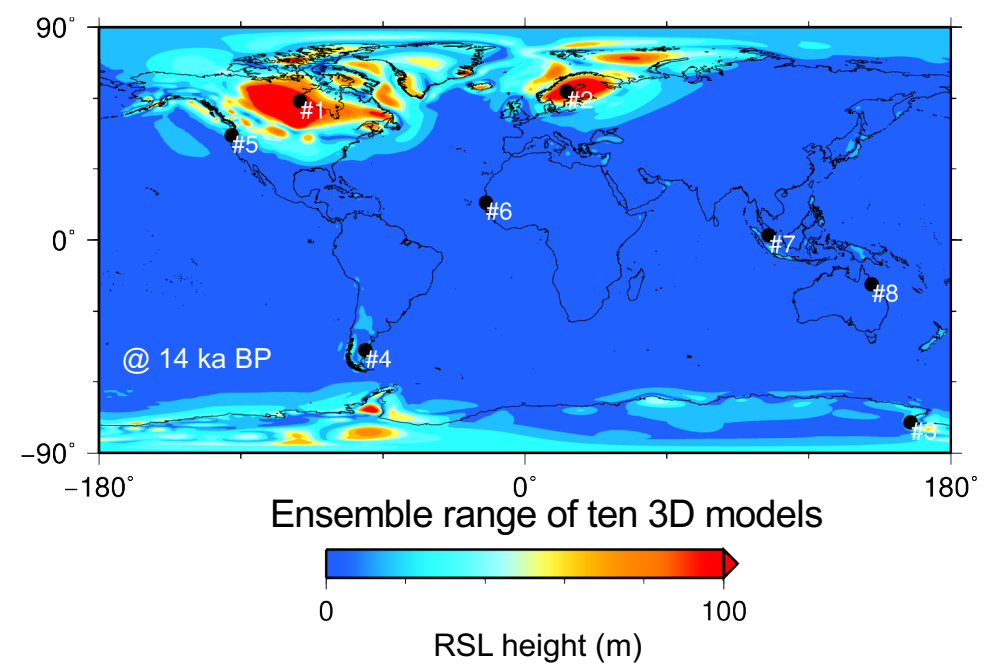

b)

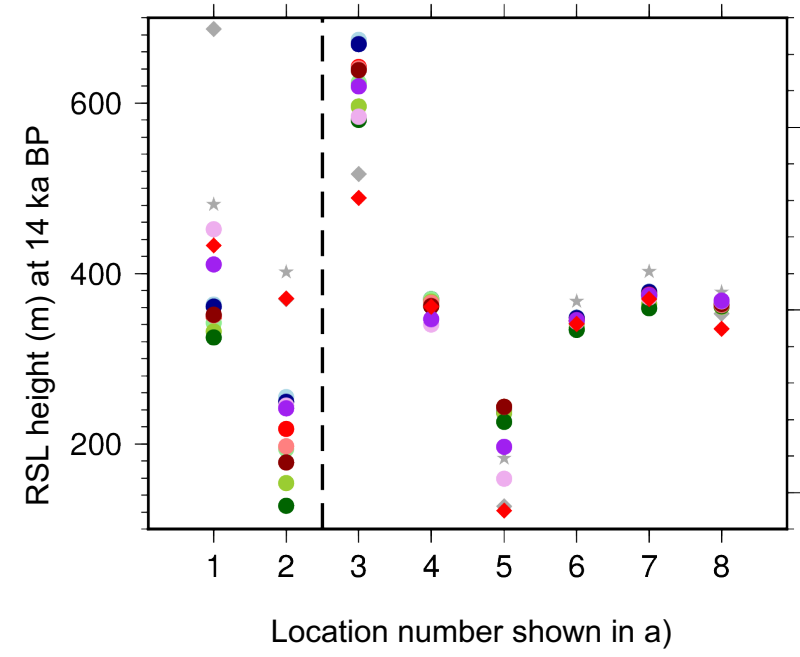

3D models

- $\mathrm{m} 0.2857$

0

- m_0.3

- m-0.4

- m 0.5

- m-0.75

- m 1.0

- m_0.4_4:3

- m $0.45: 3$

- m_0.4_sc06

- m_0.4_sc06b

1D models

- m $0.4^{*}$

- VM̄2

* VM5a

Significant variability in RSL between 3D models 


\section{Example - Earth structure}

\section{Central Oregon Coast}
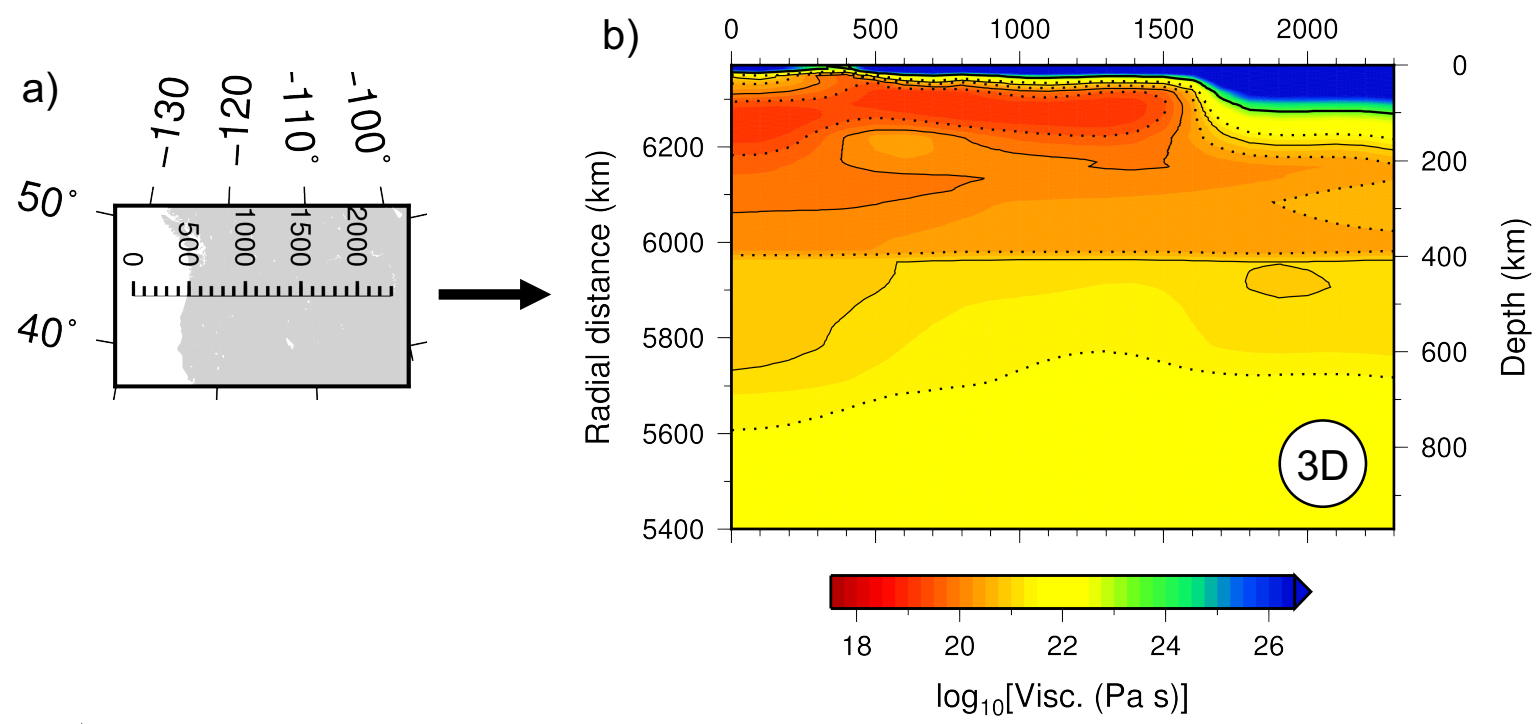

$\square$ Highly heterogeneous Earth structure with strong viscosity contrast c)

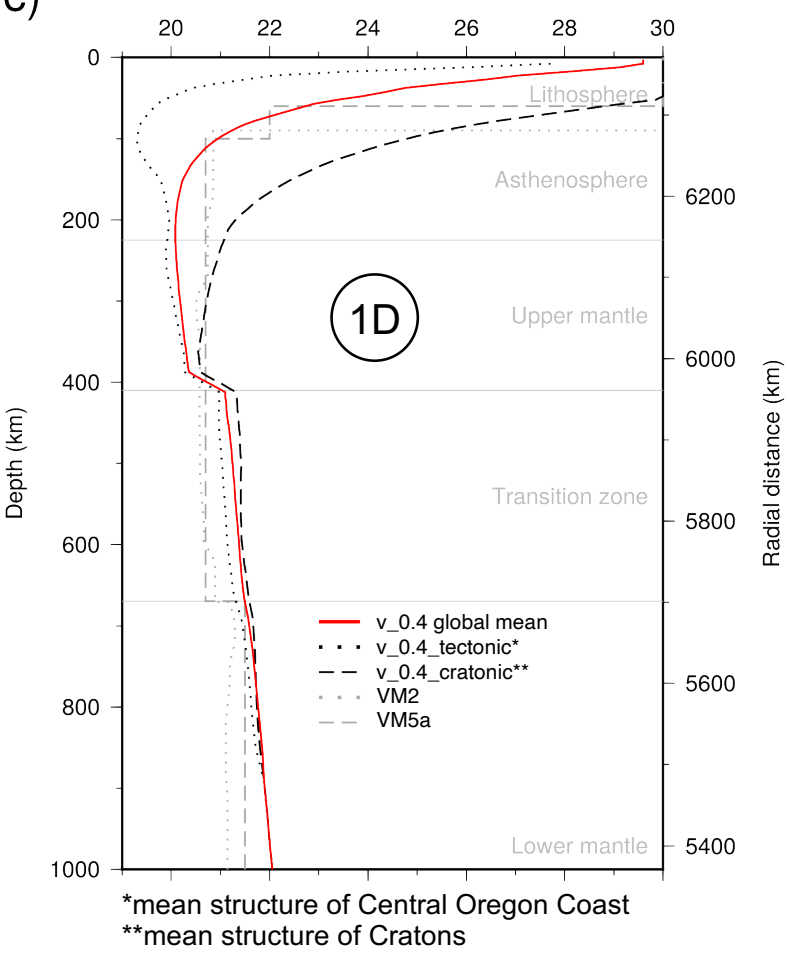




\section{Example - RSL}

\section{Central Oregon Coast}

a)

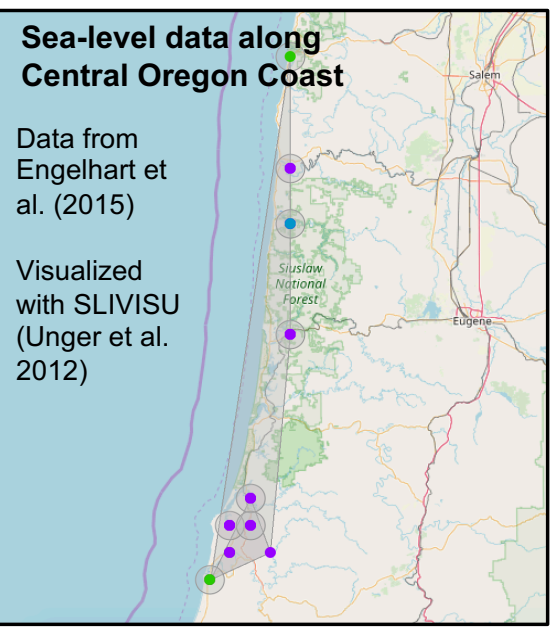

b)

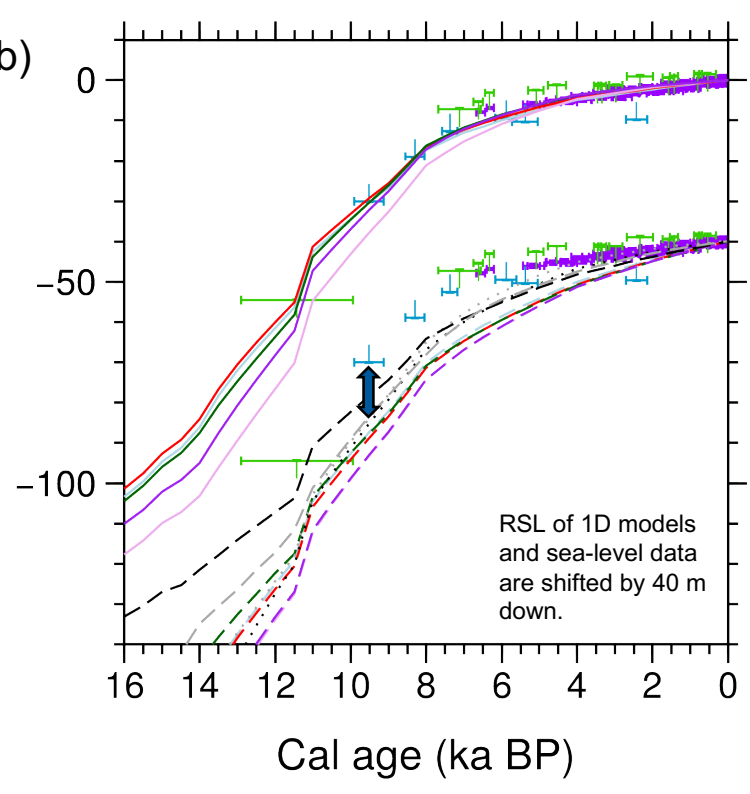

$3 \mathrm{D}$ models

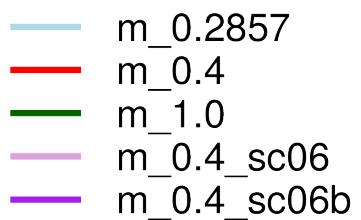

1D models

- m m 0.2857

$--m-0.4$

$--m_{-1.0}$

- - m_0.4_sc06

-- m_0.4_sc06b

- m_0.4_tectonic

- - m_0.4_cratonic

". V VM̄2

- - VM5a

*consider global mean structures 


\section{(c) (1)}

\section{Conclusions}

1. Conversion from seismic velocities to viscosity causes significant variabilities in viscosity (more than one order of magnitude) and lithospheric thickness (tens of kilometers).

2. Considered variability in viscosity can cause deviation in predicted RSL during deglaciation of more than $100 \mathrm{~m}$ at loading center. At $14 \mathrm{ka} \mathrm{BP}$, the variability amounts to $22 \mathrm{~m}$ for Ross Sea, $20 \mathrm{~m}$ for Central Oregon Coast, $7 \mathrm{~m}$ for Patagonia and mostly less than $5 \mathrm{~m}$ for farfield.

3. Example: The Central Oregon Coast is characterized by large lateral heterogeneity (Cascadian subduction zone). RSL predictions of 3D and 1D models differ significantly. While 1D models underestimate the RSL, 3D models can improve the fit to sea level indicated by geological data. 


\section{References}

- $\quad$ Clark, J., Mitrovica, J. X., \& Latychev, K. (2019), Glacial isostatic adjustment in central Cascadia: Insights from three-dimensional Earth modeling. Geology, 47(4), 295-298, doi:10.1130/G45566.1.

- Engelhart, S. E., Vacchi, M., Horton, B. P., Nelson, A. R., \& Kopp, R.E. (2015), A sea-level database for the Pacific coast of central North America, Quaternary Science Reviews, 113, 78-92, doi:10.1016/j.quascirev.2014.12.001.

- Hagedoorn, J. M., Wolf, D., \& Martinec, Z. (2007), An estimate of global mean sea-level rise inferred from tide-gauge measurements using glacial-isostatic models consistent with the relative sea-level record. Pure Appl. Geophys., 164(4), 791-818, doi:10.1007/s00024-007-0186-7.

- Klemann, V., Martinec, Z., \& Ivins, E. R. (2008), Glacial isostasy and plate motion. Journal of Geodynamics, 46(3-5), 95-103, doi:10.1016/j.jog.2008.04.005.

- Martinec, Z. (2000), Spectral-finite element approach to three-dimensional viscoelastic relaxation in a spherical earth. Geophys, J. Int., 142(1), 117-141, doi:10.1046/j.1365-246x.2000.00138.x.

- Peltier, W. R. (2004), Global glacial isostasy and the surface of the ice-age Earth: the ICE-5G (VM2) model and GRACE. Annu. Rev. Earth Planet. Sci., 32, 111-149, doi:10.1146/annurev.earth.32.082503.144359.

- Peltier, W. R., Argus, D. F., \& Drummond, R. (2015), Space geodesy constrains ice age terminal deglaciation: The global ICE-6G_C (VM5a) model. J. Geophys. Res.: Solid Earth, 120(1), 450-487, doi:10.1002/2014JB011176.

- Steinberger, B. (2016), Topography caused by mantle density variations: observation-based estimates and models derived from tomography and lithosphere thickness. Geophys. J. Int., 205(1), 604-621, doi:10.1093/gji/ggw040.

- $\quad$ Steinberger, B., \& Calderwood, A. R. (2006), Models of large-scale viscous flow in the Earth's mantle with constraints from mineral physics and surface observations. Geophys. J. Int., 167(3), 1461-1481, doi:10.1111/j.1365-246X.2006.03131.x.

- Unger, A., Schulte, S., Klemann, V., \& Dransch, D. (2012), A Visual Analytics Concept for the Validation of Geoscientific Simulation Models. - IEEE Transactions on Visualization and Computer Graphics, 18(12), 2216-2225. doi:10.1109/TVCG.2012.190. 